\title{
CORRECTION
}

\section{Correction to: Long-term changes in southern Australian anticyclones and their impacts}

\author{
Acacia Pepler ${ }^{1} \cdot$ Pandora Hope $^{1} \cdot$ Andrew Dowdy $^{1}$
}

Published online: 14 August 2019

๑) Springer-Verlag GmbH Germany, part of Springer Nature 2019

\section{Correction to: Climate Dynamics}

https://doi.org/10.1007/s00382-019-04819-9

In the original publication of the article, a minor error in analysis of ERA-Interim forecast rainfall caused an error in Figure 4 and legend. The corrected Fig. 4 and legend is given in this correction article.

\section{(a) 6-hour rainfall $(\mathrm{mm})$}

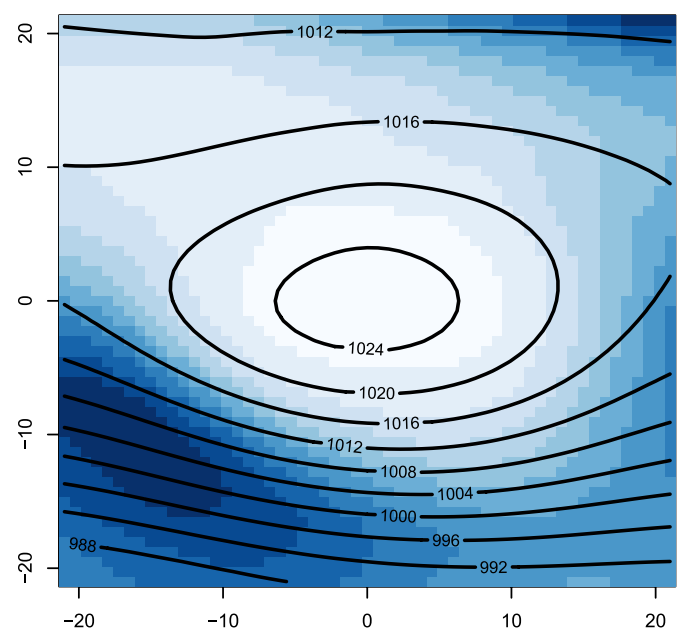

Fig. 4 Mean instantaneous sea level pressure contours (hPa) from ERAI within a $20^{\circ}$ radius of all anticyclones in the Australian region, 1980-2016, and associated $6 \mathrm{~h}$ forecast rainfall accumulation (left)

Publisher's Note Springer Nature remains neutral with regard to jurisdictional claims in published maps and institutional affiliations.

The original article can be found online at https://doi.org/10.1007/ s00382-019-04819-9.

Acacia Pepler

acacia.pepler@bom.gov.au

1 Australian Bureau of Meteorology, Melbourne, Australia (b) $2 \mathrm{~m}$ air temp anomaly (C)

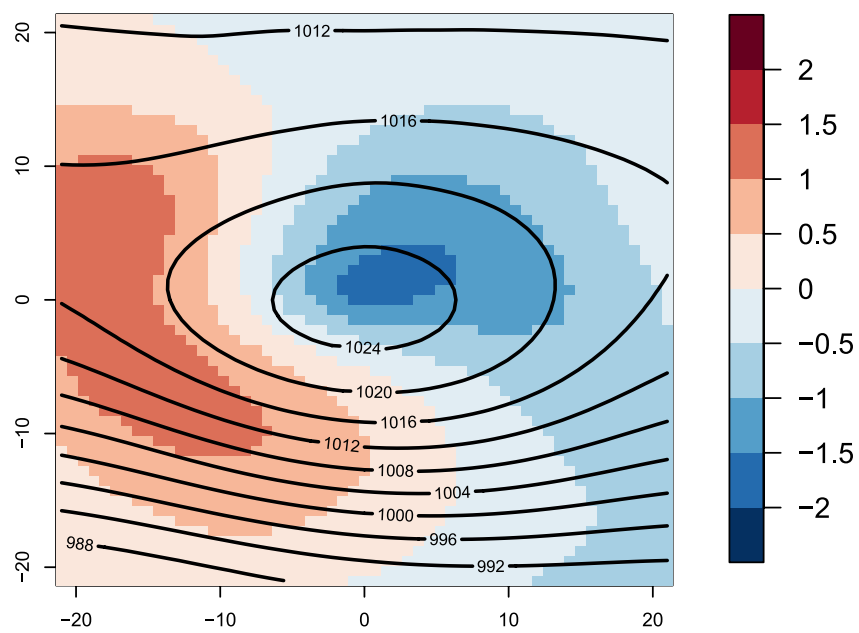

and air temperature anomaly relative to the 1979-2018 average for that hour and month (right) 